\title{
MOBILE DATA TECHNOLOGIES AND SME ADOPTION AND DIFFUSION: AN EMPIRICAL STUDY ON BARRIERS AND FACILITATORS.
}

\author{
Jeanette Van Akkeren \\ Associate Lecturer in Information Systems, \\ Faculty of Business \\ University of the Sunshine Coast \\ Sippy Downs, Queensland, Australia \\ Jvanakke@usc.edu.au \\ Debra Harker \\ Lecturer in Marketing \\ Faculty of Business \\ University of the Sunshine Coast \\ Sippy Downs, Queensland, Australia \\ Dharker@issc.edu.au
}

\begin{abstract}
The technological environment in which Australian SMEs operate can be best described as dynamic and vital. The rate of technological change provides the SME owner/manger a complex and challenging operational context. Wireless applications are being developed that provide mobile devices with Internet content and E-business services. In Australia, the adoption of ecommerce by large organisations has been relatively high, however, the same cannot be said for SMEs, where adoption has been slower than other developed countries. In contrast, however, mobile telephone adoption and diffusion is relatively high by SMEs. Will SMEs who have been reluctant to adopt ecommerce technologies in the past be more ready to go on-line with the merging of the Internet and mobile data technologies? This exploratory study identifies attitudes, perceptions and issues for mobile data technologies by regional SME owner/managers across a range of industry sectors. The major issues include the sector the firm belongs to, the current adoption status of the firm, the level of mistrust of the IT industry, the cost of the technologies, and the applications and attributes of the technologies.
\end{abstract}

Keywords: Mobile data technologies, ecommerce, SME, adoption, Internet

\section{INTRODUCTION}

The technological environment in which Australian SMEs operate can be best described as dynamic and vital. The rate of technological change provides for the SME owner/manger a complex and challenging operational context. Whilst IS literature discusses the adoption of new technologies amongst SMEs, the latest technology, the mobile data technologies and associated 'wireless' applications, presents new problems for adoption and diffusion for SME owner/managers. How, for example, can needs be assessed for a technology that does not yet fully exist? The primary appeal of these mobile data technologies apart from mobility is that associated 'services' are delivered on existing devices such as mobile phones, palm-tops, and personal digital assistants (PDAs). In the literature little empirical work exists on applications and services that would encourage the adoption of mobile data technologies by SMEs. This study provides empirical evidence on attitudes of SME owner/managers in a regional setting to mobile data technologies, and identifies the most significant facilitators and inhibiters to adoption.

The development of gateway technologies for service providers supporting WAP are already available and on the market. Further, wireless applications are being developed that provide mobile devices with Internet content and E-business services. These mobile data technologies are expected to affect business in a similar fashion to the Internet and World Wide Web a few years ago (Semilof 1999). The major appeal of mobile data technology is that it provides information to the mobile user such as reading news, getting stock quotes, sending email, downloading data, locating other users, remote access of home and business sites, and making purchases on a device that consumers are comfortable with - the mobile telephone.

The adoption of mobile telephones in the past five to ten years for voice services and messaging, by both small and large organisations in Australia, has been high. Helping to accelerate the demand for the newer mobile data technologies in countries already embracing the technologies (such as Japan) is the explosive growth of the Internet and mobile computing (Clever 1999). In Australia, this provides somewhat of a conundrum. Although adoption of ecommerce by large organisations in Australia has been relatively high, the same cannot be said for SMEs, where adoption has been slower than other countries, such as Singapore, the United Kingdom, the United States of America and Japan (Forrester Research Incorporated 1997, Yellow Pages Australia 1999). In contrast, however, mobile telephone adoption and diffusion is relatively high by SMEs. The conundrum is, therefore, will SMEs who have been reluctant to adopt ecommerce technologies in the past be more ready to go on-line with the merging of mobile voice and mobile data technologies? 


\section{LITERATURE REVIEW}

Early studies addressing the adoption of IT provide insight into reasons why decision-markers adopt or do not adopt innovations. The Diffusion of Innovation theory posited by Rogers (1995) suggests that characteristics of innovations help to persuade potential adopters to embrace or reject an innovation. Other researchers have since completed work resulting in modifications to Rogers' original theory that provide numerous models that address IT adoption and usage within an organisation.

The Technology Acceptance Model addresses IT adoption, implementation and diffusion in terms of perceived ease of use and perceived usefulness based on behavioural intentions (Davis 1989). Belief about the system, perceived usefulness and perceived ease of use is posited as directly affecting attitude to use (Rogers 1995, Agarwal and Prasad 1997). Further studies suggest that behaviour is a direct function of behavioural intention and perceived behavioural control that will impact on decision-makers choosing whether to adopt an innovation Azjen 1991, Taylor \& Todd 1995). Therefore in the adoption of mobile data technologies, will the same behavioural/psychological factors impact on the decision by owner/managers to adopt mobile data technologies? Constructs used in the above models are generally based around perceptions, beliefs, attitudes and intentions of the decision-maker. More recent studies have identified other factors in addition to these that will impact on an owner/manager's decision to adopt new innovations such as mobile phones and Internet technologies. These include economic factors such as return on investment and characteristics of the firm such as the size, sector and status, and the structural sophistication of the firm.

\section{Adoption of IT/Ecommerce by SMEs}

Empirical studies have identified a variety of factors thought to affect e-commerce/Internet technology adoption in small business (Julien \& Raymond 1994, Brooksbank, Kirby, and Kane 1992, Kirby \& Turner 1993, lacovou, Benbasat, and Dexter 1995, Tayl;or \& Todd 1995, Harrison, Mykytyn, and Rienenschneider 1997). From the adoption factors identified in earlier studies a model (figure 1) was developed based on the study on the adoption of e-commerce technologies thought to facilitate or inhibit technology adoption by SME owner/managers (Van Akkeren \& Cavaye 1999). It was on this basis that attitudes and perceptions of SME owner/managers were assessed on the adoption of mobile data technologies for this current study.

Figure 1: Framework of SME Adoption of Innovations

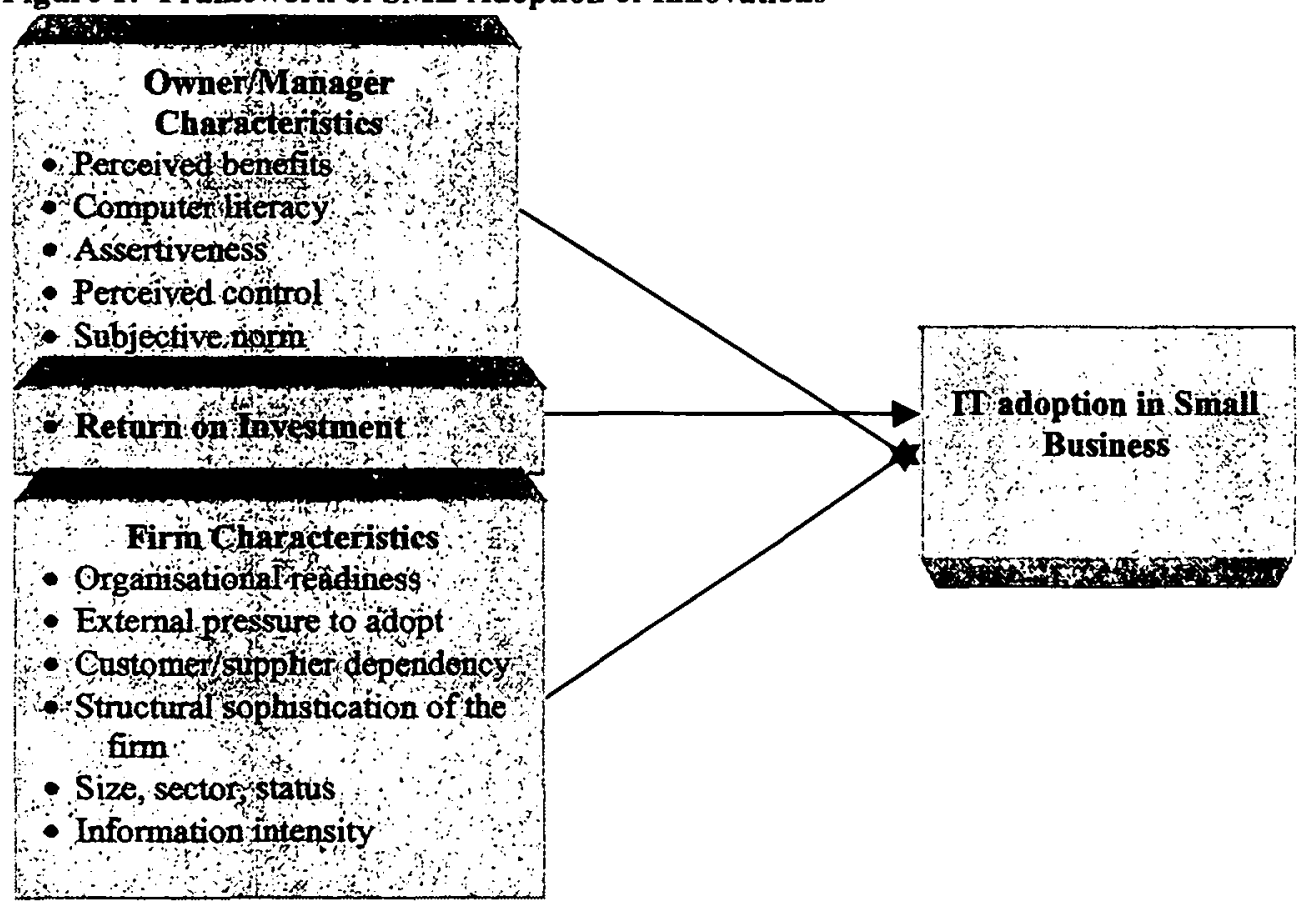

(Source: Van Akkeren and Cavaye, 1999)

The three categories presented in the framework, thought to impact on the adoption of IT innovations, provided areas of discussion for the focus groups in the exploratory stage of this research. Participants were encouraged to discuss their attitudes and perceptions of IT adoption in general and mobile technologies in particular. 
Recent studies on reasons why SME owner/managers adopt or do not adopt information technology (IT) and ecommerce technologies have highlighted both inhibitors and facilitators to adoption and are similar in content to the factors described above. SME adoption is discussed as being determined by decision-maker characteristics, information system (IS) characteristics, organisational characteristics and environmental characteristics (Thong 1999). In this study it was found that the need for IS to offer better alternatives to existing practices is critical to adoption by SMEs. Therefore, could the use of mobile data technologies provide the 'better service' that SME owner/managers seek?

Owner/manager characteristics, planning orientation, and the existence of alliances/networks are suggested by as influencing technology adoption by SMEs (McGregor \& Gomes 1999). Specifically in terms of alliances/networks, previous literature also suggests that the decision to adopt or not adopt IT will be influenced by the network within which the small business operates, particularly if time, cost and operational efficiencies can be realised (Piovesana, and Raush 1998, Lawrence 1998, Sillence, MacDonald, Lefang and Frost 1998). In contrast, in a study of SMEs in the UK, it is proposed that adoption of IT will be improved through education of the benefits of the technologies, and by fostering a planning orientation to IS design and implementation (Bridge \& Peel 1999).

In an Australian study on IT adoption by SMEs, adoption decisions are identified as having three distinct phases (Fink 1998). These are: assessing IT benefits, organisational culture and firm-suited IT; assessing internal resources and procedures; and evaluating external environment, support and services. In terms of mobile data technologies, one could argue that owner/mangers would need to assess what, if any benefits can be derived by adopting the technologies and whether their firm was suited to their adoption. Part of that evaluation would necessarily need to include both the internal and external environment in which the firm operates.

\section{Adoption and Diffusion of Mobile Data Technologies}

Major innovations may have to 'prove themselves' in new markets before they can displace other technologies (Friar and Balachandra 1999). It is the early adopters or innovators who will initially experiment with these technologies. In addition, the usefulness and ease-of-use will impact on owner/manager acceptance of the technologies (Agarwal and Prasad 1997). Therefore the attributes of the technologies may improve their acceptance by SME owner/managers. The acceptance of web-based technologies is also influenced by ease of use and perceived usefulness in terms of current IS sophistication, complexity of the new technologies, and perceived costs and benefits (Nambisan and Wang 1999).

In Australia, the adoption of Internet/e-commerce technologies varies in different states, and further, between regional and city-based firms. However, the adoption of mobile phones is consistently high across states and regions within Australia. Mobile data technologies, which 'marry' mobile phones and e-commerce technologies, are seen as eliminating time and distance as barriers for regional businesses in their adoption of these technologies.

Estimates put usage of mobile data technologies as one billion worldwide by 2003 (Greengard 2000), or US $\$ 1.3$ trillion in relation to annual turnovers by 2003 in the US alone (Thurston 2000). With such potential markets available to the vendors of mobile data services and devices, it is useful to understand reasons why the majority of potential end-users are so far resisting these new technologies.

Lack of speed is a barrier to adoption as mobile data technologies are slow and hence inefficient (Taylor 1999, Saunders, Heywood, Dornon, Bruno and Allen 1999). Another barrier is the lack of standardised IT environment for developing mobile data applications as impeding the growth of the mobile data market (Harrison 1999, Axby 1998). Limited bandwidth, higher usage costs, increased latency, and a susceptibility to transmission noise and call dropouts are also possible barriers to adoption (Duffy 1999, Johnson 1999). It is possible therefore that adopters are 'sitting back' and waiting for at least some of these problems to be corrected before entering the mobile data market. Another area of concern for end-users is that the Wireless Application Protocol, the emerging technology used to send data to and from handheld devices, has no security mechanisms built into it Osowski 1999, Chan 2000). This is concerning not only to the business user, but to the customers of the business as well.

Capturing users requires 'transparency', that is, users want information or communication access whenever and wherever they need it, using whatever device is most convenient at that moment (Osowski 1999). SME owner/managers do not buy technology; they buy business benefits (Duffy 1999). Mobile data technology benefits include easy communication through e-mail, ready access to information (wherever/whenever), entertainment, and improved lifestyle through e-commerce and home banking.

Clearly, the literature on mobile data technologies to date underlines the importance of highlighting the benefits of using the technologies, and the ease of use to potential users. SME owner/managers are not interested in the architecture, standardisation issues or the technologies themselves, instead they require a device that provides efficient, effective access and communication applications personalised to their individual needs. 
Most literature on the adoption and marketing of mobile data technologies is not empirically based and is limited to discussing the technologies in terms of their application to business, rather than adoption barriers. A distinction that can be made when determining adoption by decision makers in Australian SMEs can be based on firms in different states, and further, regional versus city-based firms. Mobile computing is seen as eliminating time and distance as barriers for regional businesses in their adoption of these technologies, particularly in relation to the design of work and for reaching potential markets. However, many regional areas of Australia have been less prepared to adopt Internet and ecommerce technologies compared to their city-based counterparts. This current study will provide a deeper understanding of the facilitators and barriers to the adoption of mobile data technologies by SME owner/managers in a regional setting. Insight will be provided on the types of applications that potential business customers require

\section{METHODOLOGY}

Two focus groups were conducted with respondents in each usage group, non-adopters, partial-adopters and fulladopters of information technology, covering a variety of industry sectors. Descriptions of each groups are:

- Full-Adopter:

- Partial-Adopter:

Used computer and Internet for business, email, ecommerce, website.

- Non-Adopter: $\quad$ No use of computer for business purposes.

Used computer for business, some use of Internet for business/home but no website.

Selection of respondents was based on two main criteria: current technology adoption status of the firm and the industry sector the firm belonged to (based on Australian and New Zealand Industry Classification (ANZIC) categories). As much as possible, a range of industry sectors was represented in each of the focus groups as different industry sectors have different needs in terms of technology adoption and usage (Van Akkeren and Cavaye, 1999). Every respondent was the owner/manager of the firm as they make all the management decisions relevant to the enterprise, including technology adoption and usage.

Attendance at the focus groups was vital to the integrity of the research, thus a rigorous procedure was adopted to increase response rates. A database of SME contacts on the Sunshine Coast was developed by research assistants and a recruitment screening questionnaire was crafted by the researchers. The questionnaire succeeded in categorising respondents into usage groups and industry sectors and an incentive of a $\$ 50$ gift voucher, redeemable at a local coffee shop, or restaurant, or cinema was used to encourage people to attend. The groups were scheduled towards the end of the working day and in the evening, which were found to be the times that best suited this type of business-person. A letter of confirmation was mailed and faxed to willing participants on the day of recruitment and a telephone call made on the day of the group to ensure attendance and alleviate any concerns. Great care was taken to ensure respondents had a positive experience of the focus group process. For example, maps were included in the mail out, ushers were on hand to escort small groups of respondents from a meeting place to the focus group room, welcoming beverages and finger food were provided, University promotional material was distributed, and networking was encouraged.

One of the key procedures in the protocol was to ask respondents before the group began to select the provider of their gift voucher and to assure them that the gift voucher would be mailed to them within the week. This was an important step in the process as recruitment promises were fulfilled before the focus group began, thus building a feeling of trust amongst respondents. The groups were video-recorded and respondents were informed before commencement about the process and reasons were provided as to why it was necessary to record the group. Respondents were then given the option of leaving the group if they were not happy being recorded. No one left. It is worthwhile to record this protocol for focus group recruitment because it provided a number of significant benefits. First, positive public relations were apparent for the University, Nortel Networks and marketing research practices in general. Second, attendance at the groups was better than expected (table 1). It is common practice to over-recruit for focus groups as there is a natural drop-out rate of $3-4$ people on the day of the group but this was not found in this project, using this protocol. 
Table 1: Focus Group Attendance

\begin{tabular}{|l|c|c|}
\hline Category & Group Time & Respondents \\
\hline Non-adopters & 5pm Wednesday 24.11.99 & 10 \\
\hline Non-adopters & 7pm Wednesday 24.11.99 & 9 \\
\hline Partial-adopters & 4pm Monday 22.11.99 & 15 \\
\hline Partial-adopters & 7pm Tuesday 23.11.99 & 11 \\
\hline Full-adopters & 7pm Monday 22.11.99 & 14 \\
\hline Full-adopters & 4pm Tuesday 23.11.99 & 12 \\
\hline
\end{tabular}

Focus groups ran for approximately one-and-a-half hours and were video-taped with the permission of respondents. Questions were asked about current technology usage and respondents were encouraged to discuss their experiences, attitudes and perceptions of information technologies. After showing a brief video that demonstrated mobile data technologies, respondents were then encouraged to discuss their reactions to these new technologies and possible applications to their industry sector. The focus group topic guide was informed by the model developed from the literature review and in collaboration with Nortel Networks. Data analysis was conducted using the content analysis approach.

Gifts vouchers were mailed to respondents at a later date, together with a Nortel Networks pen and promotional material.

\section{FINDINGS}

\section{Problems with, and praise for, IT}

After a brief introductory session, full- and partial-adopter respondents were asked to discuss any problems with, and praise for, IT in general.

\section{Problems with IT}

Whilst there was some overlap in the areas of problems with IT cited by both full- and partial-adopters, certain issues were mentioned by only one group. For example, 'pricing and costs' were areas of concern for fulladopters only, and they perceived a link between IT and these areas. Combining new ways of trading (for example on the Internet) with the move to relocate manufacturing plants to offshore locations, full-adopters felt that competition has risen to new heights:

"there's always a cheap copy available somewhere ... people appreciate the quality but they're not prepared to pay for it" (F, Clocks, 3)

"people will access the Internet, find the cuckoo clock they want ... press their button and they've got it there!"

( $F$, Printing, 25)

A second area of problems with IT, recognised by both full and partial-adopters, related to the 'reliability and support' of IT products and services. There was criticism about the rate of change in the area of innovation and, in more practical terms, strong feelings of frustration about the usefulness of IT manuals:

"the gap between the promises and the deliverables is quite huge"

(F, Health Foods, 2)

"it's the pace of change - six months and it's out of date" (F, Retail, 2)

"I'm on the phone constantly every 2 or 3 days, 'how do I do this?"'

( $P$, Convenience Store, 2)

"I'd like to be able to read a manual" (F, Apartments, 2)

"the information on how the hell the damn thing works is a nightmare!"

$$
\text { (P, Travel Agent, 5) }
$$

However, there were useful suggestions to address the latter concern:

\footnotetext{
${ }^{1}$ Where direct quotations are made from respondents, the reference is given as 'full-adopter' $(F)$, 'partialadopter' (P), 'non-adopter' $(\mathrm{N})$, followed by an industry descriptor and number of employees. 'partial-adopter' (P), 'non-adopter' (N), followed by an industry descriptor and number of employees.
} 
"an instruction manual on a video disk ... instead of words there's a picture of someone" (F, Electronics, 2)

Similarly, both full- and partial-adopters cited 'compatibility' as an area of frustration with IT. This related to computers, consumables (such as printer cartridges), and attachments in email:

"you get something that's sent by email and you can't open it up and that's a real pain" (P, Signage, 3)

A key difference between these two groups of adopters was the issue of 'fear'. Full-adopters did not display any fear about working with technology, however partial-adopters realised they needed to use IT to demonstrate the currency, and therefore dynamism, of their business, in spite of their reservations:

"one good thing IT gives is the appearance you know what you're doing"

( $P$, Hairdresser, 5)

"if I present something into one of my shops which is a little bit high tech the girls will look at it and think 'I'm a hairdresser, not a computer whiz' so they're a little scared of this technology' $(P$. Hairdresser, 5)

Being low users of technology, non-adopters in the groups were asked why they did not use it. The most important reason cited by them was 'cost', together with:

$$
\begin{aligned}
& \text { - losing data } \\
& \text { - obsolescence } \\
& \text { - no need/benefit } \\
& \text { - time consuming } \\
& \text { - power failures }
\end{aligned}
$$

- maintenance

- lack of suitable training

- viruses

- break downs

- impersonal

Understandably, there was also the issue of 'fear' with non-adopters; fear of buying the wrong technology, or about their own ability to learn new technology:

"if you write things out you don't have to worry if you press the wrong button and something gets lost" $(N$, Home Maint., 2)

All of these problems were couched in business terms, that is, all of the areas were felt to negatively affect business practices.

\section{Praise for IT}

Many full and partial-adopter respondents were willing to tolerate the frustrations of technology, given the positive impact it made on their lives. Speed was the main advantage mentioned about technology and this had implications for business practices. Many cited the increased improvement and decreased cost of technology over the years:

"we bought a computer at approximately one third of the price of the one we bought four years ago, it's probably ten times more valuable, fifteen times more storage"

\section{Innovations}

(F, Health Foods, 2)

Respondents in all groups were asked to suggest the main innovations in IT over the past five years. The following table displays the responses of all groups: 
Table 2 - Innovations

\begin{tabular}{|c|c|c|}
\hline Innovation & Benefits & Typical Comments \\
\hline $\begin{array}{l}\text { Mobile } \\
\text { Phone: }\end{array}$ & Freedom, flexibility, convenience, availability. & $\begin{array}{c}\text { "if you miss out on a deal, you miss out } \\
\text { on money" ( } N \text {, Boutique, 2) }\end{array}$ \\
\hline Computer: & $\begin{array}{l}\text { Speed, control (inventory, accounting), data } \\
\text { storage, letters, retrieving information. }\end{array}$ & $\begin{array}{c}\text { "we used to have two rooms of books, } \\
\text { now we have one shelf of CDs" } \\
(F, \text { Solicitor, } 4)\end{array}$ \\
\hline Internet: & $\begin{array}{l}\text { Information, world trends, check prices, } \\
\text { website, competitor information, cost effective } \\
\text { (e.g. sending samples of work via email), } \\
\text { convenience, speed, current. }\end{array}$ & $\begin{array}{l}\text { "it's more convenient than getting the } \\
\text { Yellow Pages out" (F, Resort, 9) }\end{array}$ \\
\hline EFTPOS: & $\begin{array}{l}\text { Speed, streamlined service, cashless society, } \\
\text { enhanced security, keeping up with } \\
\text { competitors, add-on sales, impulse buying, } \\
\text { security, keep up with competitors. }\end{array}$ & $\begin{array}{c}\text { "we rarely take cheques ... generally } \\
\text { credit cards, and that means big } \\
\text { business" (F,TV Service, 14) } \\
\text { "the money is immediately in your } \\
\text { bank" } \\
(N, \text { Shoes, } 3)\end{array}$ \\
\hline $\begin{array}{l}\text { Desktop } \\
\text { banking: }\end{array}$ & $\begin{array}{l}\text { Immediacy, ease of moving money around, } \\
\text { payroll, bill paying, remote operation: }\end{array}$ & $\begin{array}{l}\text { "we operate shops in Rockhampton } \\
\text { and on payday ... just highlight the } \\
\text { people we want to pay and then } \\
\text { schunk!" ( } F, \text { Printing, } 25)\end{array}$ \\
\hline Fax: & $\begin{array}{l}\text { Speed, time and money saving, direct } \\
\text { communications, visual. }\end{array}$ & $\begin{array}{l}\text { "you come in and the floor's full of it, } \\
\text { all the orders" (N, Boutique, 2) } \\
\text { "we do all our work by fax" (P, Dry } \\
\text { Clean, 9) }\end{array}$ \\
\hline $\begin{array}{l}\text { Barcoding/ } \\
\text { scanning: }\end{array}$ & $\begin{array}{l}\text { Currency of information (e.g. stock levels), } \\
\text { competitive advantage. }\end{array}$ & \\
\hline Databases: & Tracking, reports, mailouts. & \\
\hline Networking: & $\begin{array}{l}\text { Linking PCs together, reduces costs, increases } \\
\text { speed. }\end{array}$ & \\
\hline $\begin{array}{l}\text { Operating } \\
\text { Systems \& } \\
\text { software: }\end{array}$ & $\begin{array}{l}\text { Moving from DOS to Windows and NT - } \\
\text { better for business. }\end{array}$ & \\
\hline Printers: & Higher quality, cheaper now. & \\
\hline Scanners: & $\begin{array}{l}\text { Time and cost of producing high quality work } \\
\text { reduced now. }\end{array}$ & \\
\hline $\begin{array}{l}\text { Video } \\
\text { Cassette } \\
\text { Recorder: }\end{array}$ & $\begin{array}{l}\text { Demonstrate business (if appropriate) (only } \\
\text { mentioned by non-adopters) }\end{array}$ & \\
\hline
\end{tabular}

\section{Internet Usage and Adoption Behaviour}

Full-adopters were Internet users and most had their own website. They tended to use the Internet as a business component and competitive edge, for example to sell their goods and services, rather than buy, and to generate enquiries:

"we get a lot of enquiries on email in the holidays, from all over the world ... Tasmania, Ireland" (F, Resort, 9) "people say they've seen your web page ... that's a positive aspect"

\section{( $F$, Mobile Hairdresser, 2)}

By definition, partial-adopters were not significant users of the Internet for business purposes. Those that did use the Internet did so in response to pressure from competitors, customers, or suppliers. Non-adopters did not use the Internet and so were asked about family use; many had children who used the Internet, either as part of their education, or actually working in the IT industry: 


\section{"they're brought up with it" (N, Designs, 1)}

All respondents were asked to comment on their use or intended use of Teletext and Digital Televisions. Whilst full-adopters were the most aware (of all three types of IT users) when it came to Teletext, the were not supporters; indeed, those that had used it found it to be too slow and not interactive enough:

"there are over 600 pages, but there's only three you ever want!" (F, Apartments, 2) "it's very ... dull" (F, Health Food, 2)

Partial- and non-adopters of IT did not use Teletext.

When asked about Digital TV, full- and partial-adopters were wary, waiting for government standards to be established before buying, and also for, what they felt would be, the inevitable price decrease after launch. Nonadopters had no interest:

"the price will be astronomical, it'll come down ... just like the old colour TVS ... it's like we're changing from black and white to colour" (F, Property Developer, 2)

"when they come down to about $\$ 1,000$ after about 6 years" ( $P$. Car Electrics, 4)

\section{Product/Service Applications Video}

The Nortel Networks video was shown in all groups and then responses elicited about product/service application needs and benefits.

\section{Initial Reactions}

Full-adopters were visibly stimulated by the video, displaying knowledge of the area and being keen to discuss future applications:

"we're not very far away from a lot of these things ... I witnessed a digital camera take a photo and he hooked it up to his mobile phone and sent it to someone" (F, Printing, 25)

Partial-adopters were unenthusiastic about the technology demonstrated in the video, being very wary, cautious and fearful:

"I wouldn't want one of those because it'd be 'where are you?' and they would be onto me" (P, Dry Clean, 9)

"I wouldn't like it" (P, Signage, 3)

The reaction of the non-adopters was somewhere between the full- and partial-adopters; when asked, half of the non-adopters wanted one of the handsets, mainly to stay in touch with the youth and technology in general, whilst the other half did not see a need. However, they were overwhelmed, initially, by the technology demonstrated:

$$
\text { "we couldn't take it all in!" (N, Shoes, 3) }
$$

Respondents then participated in an exercise whereby the services demonstrated in the video were listed, benefits associated, and then the services ranked in order of importance. Tables 3, 4 and 5 display this information for each adopter level: 
Table 3 - Services (Full-adopters)

\begin{tabular}{|l|l|c|}
\hline Service & Benefits & \multicolumn{1}{c|}{ Typical Comments } \\
\hline $\begin{array}{l}\text { 1. 2 way } \\
\text { video/voice/ } \\
\text { voice recognition }\end{array}$ & $\begin{array}{l}\text { Relationship marketing, the power of } \\
\text { face-to-face persuasion, personalised } \\
\text { and improved customer service, speed, } \\
\text { time, planning: }\end{array}$ & $\begin{array}{c}\text { "international business is a very } \\
\text { personal thing" }(F, \text { Exports, } 17)\end{array}$ \\
\hline $\begin{array}{l}\text { 2. Prioritising \& } \\
\text { screening messages }\end{array}$ & $\begin{array}{l}\text { Delegation of work to others, freedom, } \\
\text { cost savings on labour, rent overheads: }\end{array}$ & $\begin{array}{c}\text { "no one would have to be in one } \\
\text { particular office space" } \\
\text { (F, Fencing, 6) }\end{array}$ \\
\hline $\begin{array}{l}\text { 3. Remote access } \\
\text { Ability to check home/business from } \\
\text { another location, security, peace of } \\
\text { mind, working smart: }\end{array}$ & $\begin{array}{c}\text { "if it wasn't okay I could push } \\
\text { another button and get Security guys } \\
\text { there straight away" } \\
\text { (F, Property Developer, 2) }\end{array}$ \\
\hline $\begin{array}{l}\text { 4. Online } \\
\text { information }\end{array}$ & $\begin{array}{l}\text { Voice searching on the Internet or } \\
\text { specialist databases: }\end{array}$ & $\begin{array}{l}\text { I could check the chlorine levels in } \\
\text { my pool" (F, Apartments, 2) }\end{array}$ \\
\hline $\begin{array}{l}\text { 5. Attachments, } \\
\text { downloading }\end{array}$ & Ability to send information to others. \\
\hline 6. Navigation & $\begin{array}{l}\text { Directions, deviations, detours, speed, } \\
\text { time, planning. }\end{array}$ & (F, Solicitor, 4) \\
\hline 7. Translation & Useful for international transactions. \\
\hline
\end{tabular}

Table 4 - Services (Partial-adopters)

\begin{tabular}{|c|c|c|}
\hline Service & Benefits & Typical Comments \\
\hline $\begin{array}{l}\text { 1. Remote access } \\
\text { \& security }\end{array}$ & Control & $\begin{array}{c}\text { "you don't have to go into work ... } \\
\text { just put that machine on and see } \\
\text { what's happening" (P, Coffee House, } \\
12) \\
\text { "I don't need to sit at the computer } \\
\text {... just walk around the store chatting } \\
\text { to it!" (P, Conv. Store, } 2)\end{array}$ \\
\hline $\begin{array}{l}2.2 \text { way } \\
\text { communication: } \\
\text { video/voice/ } \\
\text { voice recognition }\end{array}$ & $\begin{array}{l}\text { Speed, communication, mobility, } \\
\text { immediacy, ease of use, improved } \\
\text { communication means improved } \\
\text { customer relations, build loyalty. }\end{array}$ & $\begin{array}{c}\text { "you can do more than one thing at a } \\
\text { time" (P, Newsagent, } 5)\end{array}$ \\
\hline 3. Navigation & $\begin{array}{l}\text { Information - delays, detours, local } \\
\text { knowledge, time and cost savings from } \\
\text { better planning. }\end{array}$ & $\begin{array}{c}\text { "the courier guy ... hasn't had to } \\
\text { think about it, he's done it in half the } \\
\text { time ... made his run" } \\
(P, \text { Festival Org, } 1)\end{array}$ \\
\hline $\begin{array}{l}\text { 4. Prioritising \& } \\
\text { screening messages }\end{array}$ & Screen messages, screen ads out. & \\
\hline
\end{tabular}


Table 5 - Services (Non-adopters)

\begin{tabular}{|l|l|c|}
\hline Service & Benefits & \multicolumn{1}{c|}{ Typical Comments } \\
\hline $\begin{array}{l}\text { 1. 2 way } \\
\text { communication: } \\
\text { video/voice/ } \\
\text { voice recognition }\end{array}$ & $\begin{array}{l}\text { Sending samples, time saved on travel } \\
\text { and answering calls, freight costs } \\
\text { reduced, business networking } \\
\text { opportunities }\end{array}$ & $\begin{array}{c}\text { "you can see who you're talking to" } \\
\text { (N, Hairdresser, 2) }\end{array}$ \\
\hline $\begin{array}{l}\text { 2. Navigation } \\
\text { Save time. }\end{array}$ & $\begin{array}{l}\text { "the map business ... Iloved that, } \\
\text { that was excellent!" N, Boutique, 2) }\end{array}$ \\
\hline $\begin{array}{l}\text { 3. Remote access } \\
\text { \& security }\end{array}$ & Both business and home needs. & \\
\hline 4. Shopping & & \\
\hline
\end{tabular}

Full-adopters had the clearest thinking about how they would use this technology - immediately. Their discussions centred around how their top three ranked services would interact and the impact this would have on their business practices. For example, they were the only group of adopters who included 'prioritising messages' in their top three (table 6), with the key benefit of delegation of tasks. There was also discussion in these groups about screening of junk messages and to prioritise messages, suggestions included screening by time of day, and by different types of callers.

Table 6 - Top Three Rankings, All Groups

\begin{tabular}{|l|l|l|l|}
\hline Rank & Full-adopters & Partial-adopters & Non-adopters \\
\hline First & $\begin{array}{l}\text { 2 way communication: } \\
\text { video/voice/ } \\
\text { voice recognition }\end{array}$ & Remote access \& security & $\begin{array}{l}\text { 2 way communication: } \\
\text { video/voice/ } \\
\text { voice recognition }\end{array}$ \\
\hline Second & $\begin{array}{l}\text { Prioritising \& screening } \\
\text { messages }\end{array}$ & $\begin{array}{l}\text { 2 way communication: } \\
\text { video/voice/ } \\
\text { voice recognition }\end{array}$ & Navigation \\
\hline Third & Remote access \& security & Navigation & $\begin{array}{l}\text { Remote access \& } \\
\text { security }\end{array}$ \\
\hline
\end{tabular}

The partial-adopters were not keen to have this technology at all but when asked to rank their services, they included the navigation service, as did the non-adopters.

All groups raised concerns about the services on show. Partial-adopters were concerned about the reliability of the system, confidentiality, having no free time, the civil liberty issue and concerns about 'big brother'. Nonadopters mentioned the issue of invasion of privacy. Security of such a system was a recurring theme amongst all groups:

\footnotetext{
"what happens if you lose it (the handset)?" (F, Property Developer, 2)

"Someone else could access your home security before they go in and rob you"

$(F$, Windscreen, 4)
}

Remedies for the security concern included; using thumbprint recognition, retina scan or voice recognition.

\section{Service Delivery}

Participants were asked the type of mobile data device they would favour most, what personalisation services they would prefer, and the most appropriate pricing of the device.

\section{Handsets}

The Nortel video used to demonstrate the new technologies showed users having two or three different devices. From a practical point of view, full and partial-adopters were in agreement that they would prefer only one handset for this type of service:

"you'd be carrying this around (diary), along with this (mobile phone) and the glasses and you don't want more than one (PDA/handset) to carry around"

(F, Export, 17) 
"I find it hard enough to remember to take my bag, my purse, my car keys and get in the car with three kids, let alone three or four other devices! " $(F$, Electronics, 2)

\section{A Personalised Service}

The ability to personalise a service was welcomed by most group respondents, across all IT usage types. To be able to access certain websites, locations and services is appealing and respondents felt that this could impact on price. Some respondents, most notably the partial-adopters, were willing to take extra advertising on their handset if this reduced the price.

Respondents demonstrated their distrust of the IT industry by requesting a compatible service, one that works with other competing products and services in the marketplace, and one that is reliable:

"Telecom come out with one, Vodafone too, and suddenly you've got to be better so they add a little extra on and it's not so simple" (F, Apartments, 2)

"you'd have to pay for a service package, but then you'd have to have the service to go with it" (P, Conv. Store, 2)

\section{Price}

Many respondents made the analogous link between this type of new technology and the introduction of the mobile phone some years ago:

\section{"It's like mobile phones ... people gradually over time realised they're not so bad' ( $P$, Accountant, 8)}

This lead to a discussion on pricing with a 'user pays' approach gaining most support amongst group members:

"the way people pay for mobile phones has been instrumental in the wide acceptance of mobile phones in this country" (F, Business Supplies, 4)

For example, people were keen to have a modular approach to price, whereby they could up/downgrade as and when they needed more or less services. Thus, a rental or lease arrangement was popular, charging on a usage approach, rather than a priority of service basis, whereby they would be restricted to using the service at certain times of the day or night:

"you pay another fee per month if you want to get to talk, change it in different languages, you pay another fee, you could pay $\$ 100$ per month or $\$ 500$ per month but if you don't want any - you only want to pay $\$ 50$ per month'

(F, Property Developer, 2)

"leasing it ... when your job changes or your business grows, you just hand that one in and say 'I need the next model" " $(N$, Café, 15)

"in business you're probably going to want to be charged by use because you can't say 'I can't do that until after 10 o'clock' or something" (N, Gifts, 2)

"say, an 18 month contract but with the ability to upgrade easily" ( $P$, Art Gallery, 2)

Full-adopters, comfortable with technology, were especially able to see the value and benefits of the proposed service, consequently they would be keen to acquire the service - if it was affordable:

"we're going to rely on it more and more, that's going to be a great marketing tool and a great money-making tool for them (Nortel) so it should be priced on usage"

$(F$, Printing, 25)

\section{DISCUSSION}

It is possible to argue that there are many different factors that will impact on an SME owner/managers' decision to adopt or not adopt mobile data technologies. The industry sector the firm belongs to, the current IT adoption status of the firm, the level of mistrust of the IT industry and the cost of the technologies are highlighted in this 
study as possible barriers or facilitators to adoption. The features of the mobile device, including the applications on offer (which directly relates to perceived business benefits of the technologies) are also raised as having a possible impact on adoption.

The focus groups found significant differences in the way different types of people view and use technology. Full-adopters of technology, for example, are very open to new ideas and innovations, compared to the partialadopters, although they raise concerns about the cost of keeping up with the rate of technological change. Nonadopters, whilst being fearful of technology generally, have an open mind when presented with futuristic new technology, especially when compared to the partial-adopters. One reason for these differences could be that partial-adopters have been 'forced' to adopt technology before they were really prepared; this adoption may have been in response to customer, competitor, or supplier pressure. Thus, they are fearful; of over-reliance on technology, of being hoodwinked by IT companies, of being made to feel inadequate, and of being overtaken by others in terms of business practices.

When asked about innovation in IT in the past five years most discussion in the groups centred around the mobile phone, computers, the Internet, EFTPOS, desktop banking and the fax machine. Benefits associated with these innovations included freedom, flexibility, speed, convenience, increased information, competitive advantage, ease of use and direct communications. These reactions bode well for Nortel and the future of WAP, as the key features of WAP provide all of these benefits on a mobile device.

In terms of Internet use by the group members, full-adopters have no fear and use the technology for business and pleasure. Partial-adopters tend to have Internet technology forced upon them by competitors, customers or suppliers, whilst the non-adopters commented on family use and pressure and demonstrated a desire to 'keep up' with the youth of today, and tomorrow.

The Nortel Networks video that was used in the groups facilitated much discussion, excitement and fear, but also biased responses somewhat, especially in relation to the number of handsets or PDAs people would tolerate. Initial reactions to the video by respondents were mixed. Full-adopters were visibly excited by the prospect of the technology demonstrated, partial-adopters were unenthusiastic, cautious and fearful, whilst non-adopters were evenly divided in their interest.

Full-adopters, many of whom could be considered early adopters and innovators, would use this technology tomorrow if it were available, as long as it was affordable. The service they would most like to 'buy' is the twoway communication with video/voice recognition. This group of adopters was the most focused in their intended use of the technology, being very business-focused and seeing a need for almost all of the services on display. The non-adopters also cited the two-way communication with video/voice recognition as their favourite service and both groups felt that this service would give them improved customer relations with the face-to-face persuasion, increased speed and better use of time. Partial-adopters were reticent about the technology but felt that, if they had to choose, the ability to remotely access sites would be useful and the security aspect appealing. The greatest benefit for them would be control of the working environment. All three adopter groups were concerned with security of the system.

The issue of personalising the service was attractive to most focus group members as they are busy running a business and not interested in unsolicited messages or advertising. People also linked the personalisation issue to price, feeling that a user-pays system was fairest, with the ability to upgrade when they were ready or saw a need for more services. Group members also likened the new technology to the roll out of mobile phones in Australia, with rental plans and price based on usage levels. Respondents were not keen to have the services priced on a priority basis whereby they would be restricted to using the service at certain times of the day or night as this would impact negatively on their business practices.

The model used as the basis for the development of the focus group topic guides was useful in predicting the types of issues different adopter groups raised. However the level of emphasis placed on different constructs listed in the model varied depending on the adoption status of the owner/manager. For example, the level of mistrust of the IT industry was seen as an influencing factor by partial- and full-adopters. However, non-adopters were less concerned about this issue. This is not surprising given they have not purchased technologies and therefore are not experienced with the IT industry. Perceptions of owner/managers of the benefits of mobile data technologies appear to be an important consideration, as do the purchasing and on-going costs of the technology. The model also predicts that computer literacy, external pressure to adopt the technology, customer/supplier dependency and the size, sector and status of the firm will impact on technology adoption. Findings from the focus groups support these factors as influencing adoption of mobile data technologies.

To conclude, there are a number of issues that are apparent from this exploratory study that need to be included in a larger, quantitative study with a significant sample from the wider population. Limitations of focus groups such as the influence participants have on each other, and the intimidation some participants' experience within a group situation could be overcome with a quantitative study such as a survey or telephone interview. In addition, a greater cross-section of industry sectors would need to be included to improve the generalisability of this study. Findings presented so far may not be generalisable to other Australian capital cities. However including citybased small businesses in further work should overcome this problem. Benefits are very important to SME 
owner/managers who do not have the luxury of time to train, research, or upgrade their technology, without losing business. Thus, the quantitative study should focus upon technology use and associated benefits across different industry sectors, gauging levels of concern/comfort with technology. The study could then focus respondents on the new technology, gauge awareness, need, and services sought, building on the findings from this exploratory work.

\section{REFERENCES}

Agarwal, R. and Prasad, J. (1997), 'The role of innovation characteristics and perceived voluntariness in the acceptance of information technologies', Decision Sciences, 28, 3, 557-582.

Ajzen, 1. (1991), 'The theory of planned behaviour', Organisational Behavior and Human Decision Processes, , 179-211 in Taylor, S. and Todd, P.A., 'Understanding information technology Usage: A test of competing models', Information Systems Research, 6, 2 (June 1995),144 -176.

Axby, E. (1998), 'Creating a market for mobile data', Telecommunications, 32, 9 September, 37-39.

Bridge J. and Peel M. J. (1999), 'A study of computer usage and strategic planning in the SME sector', International Small Business Journal, London, 17, 4, 82.

Brooksbank, R., Kirby, D., and Kane, S. (1992), 'IT adoption and the independent retail business: The retail newsagency', International Small Business Journal, 10, 3 (Apr-June, 53-61.

Chan, T. (2000), 'Cracks in the WAP', America's Network, 104, 3, 26-27.

Clever, M. (1999), 'Mass Market Solutions for Mobile Data', Telecommunications, 33, 6, 40-49.

Davis, F. (1989), 'Perceived usefulness, perceived ease of use and user acceptance of information technology', MIS Quarterly, 13, 3, September, 319-340.

Duffy, R. (1999), 'Wireless set to take the lead', Telecommunications, 33, 11, 24-26.

Fink, D. (1998), 'Guidelines for the successful adoption of IT in small and medium enterprises', International Journal of Information Management, August, 18, 4.

Forrester Research Incorporated (1997), Forrester ranks world economics for eCommerce, 30 April, Cambridge, , MA, [online] <http://www.forrester.com. >, accessed August 1998.

Friar, J. H. and Balachandra, R. (1999), 'Strategies for marketing new technologies', Research Technology Management, 42, 4, 37-43.

Gefen, D., and Straub, D.W. (1997), 'Gender differences in the perception and use of E-mail: An extension to the technology acceptance model', MIS Quarterly, 21, 4, 389-400.

Greengard, S. (2000), 'Going mobile', Industry Week, 249, 1, 18-22.

Harrison, D.A., Mykytyn, P.P. .Jr, and Rienenschneider, C.K. (1997), 'Executive decisions about IT adoption in small business: Theory and empirical tests', Information Systems Research, A Journal of the Institute of Management Sciences, 8, 2, 171-195.

Harrison, H. (1999), 'WAP: The key to mobile data', Telecommunications, 33, 9, 96-98.

Hom, D. (2000), 'E-business portals ease end-user service creation', Telecommunications, 34, 1, 43-45.

Iacovou, C.L., Benbasat, I., and Dexter, A.A. (1995), 'Electronic data interchange and small organisations: Adoption and impact of technology', MIS Quarterly, 19, 4, 465-485.

Johnson, A.H. (1999), 'WAP', ComputerWorld, 33, 4469.

Julien, P.A., and Raymond, L. (1994), 'Factors of new technology adoption in the retail sector', Entrepreseurship: Theory and Practice, 18, 5, 79-90.

Kirby, D., and Turner, M. (1993), 'IT and the small retail business', International Journal of Retail and Distribution Management, 21, 7, 20-27.

Lawrence, K.L. (1998), 'Factors inhibiting the utilisation of electronic commerce facilities in Tasmanian smallto medium-sized enterprises', $8^{\text {th }}$ Australasian conference on Information Systems,.

Mahajan, V. and Muller, E. (1999), 'When is it worthwhile targeting the majority instead of the innovators in a new product launch', Journal of Market Research, 35, 4, 488-495.

McGregor, J. and Gomes, C. (1999), 'Technology uptake in SMEs: Some evidence from New Zealand', Journal of Small Business Management, 37 3, 94-102.

Mobile Data Conference (1999), Sydney, NSW.

Nambisan S. and Wang Y. (1999), 'Roadblocks to web-based technology adoption', Association for Computing Machinery, Communications of the ACM, New York, , 42, 1, 98-101.

Osowski, K. (1999), 'Unifying communications', Communications News, 36, 9, 18-20.

Piovesana, R. and Raush, B. (1998), 'The Web help small players connect', Bobbin, 39, 9, 50-51.

Riggs B. and Bachelor B. (1999), 'Vendors address issue of security for wireless devices', Informationweek, 765, 25-26.

Rogers, E.M. (1995), Diffusion of Innovations, $4^{\text {th }}$ edn, The Free Press, New York.

Saunders, S., Heywood, P., Dornon, A., Bruno, L. and Allen, L. (1999), 'Wireless IP: Ready or not, here it comes', Data Communications, 28, 12 42-68. 
Semilof, M. (1999), 'Hitting the road? Take the Internet along', Computer Reseller News, 864, 1.

Sillence, J.A.A., MacDonald, S., Lefang, B. and Frost, B. (1998), 'Email adoption, diffusion, use and impact within small firms: A survey of UK companies', International Journal of Information Management, 18, 4, 231-242.

Taylor, M. (1999), 'The need for speed', Communications International, 26, 2, 41-42.

Taylor, S. and Todd, P.A. (1995) 'Understanding information technology Usage: A test of competing models', Information Systems Research, 6, 2, $144-176$.

Thong, J.Y.L. (1999), 'An integrated model of I/S adoption in small businesses', Journal of Management Information Systems, 15, 4, , 187-214.

Thong, J. and Yap, C.S. (1995), 'CEO characteristics, organisational characteristics, and information technology adoption in small business', Omega, , 23, 4 429-442.

Thurston, C. (2000), 'Economic waves wash onto all shores', Global Finance, 14, 1, 121-123.

Van Akkeren J. K. and Cavaye A. L. M. (1999), 'Factors Affecting Entry-Level Internet Adoption by SMEs: An Empirical Study', proceedings from the Australasian Conference in Information Systems, 2, 1716-1728.

Weiers R. M. (1988), Marketing Research, (2nd edn.), Prentice Hall, , NJ.

Wexler, J. (1999), 'Cut the Cord', Upside, 11, 11, 201.

Yellow Pages Australia (1999) Small Business Index: Survey of Computer Technology and Ecommerce in Australian Small and Medium Business. 